\title{
CUPRI SYSTEM CONFIGURATION FOR NLC-91 AND OBSERVATIONS OF PMSE DURING SALVO A
}

\author{
Wesley E. Swartz, John Y. N. Cho and Clark A. Miller \\ School of Electrical Engineering, Cornell University
}

\begin{abstract}
The Cornell University Portable Radar Interferometer (CUPRI) provided nearly continuous monitoring of the mesosphere above Esrange, Sweden during the noctilucent cloud rocket and radar campaign of the summer of 1991 (NLC-91). CUPRI probed the mesosphere above Esrange from 78 to $91 \mathrm{~km}$ altitude with 300 -meter resolution and was sensitive to the enhanced Polar Mesospheric Summer Echoes (PMSE) that occur in the same altitude range as NLC formations. Out of the total of 264 hours of CUPRI observation time, PMSE were present for 140 hours. Rocket Salvo A was flown on the night of August 9-10 into an NLC event that occurred simultaneously with a thin and weakening PMSE layer. Highresolution Doppler spectrograms of this PMSE event revealed sawtooth-like discontinuities at $\sim 83 \mathrm{~km}$ altitude, which we interpret to be a distorted partial reflection layer which was advected across the radar beam.
\end{abstract}

\section{Introduction}

The details of the relationships between noctilucent clouds (see, e.g., Witt [1969], Gadsden and Schröder [1989], and Thomas [1991]) and polar mesosphere summer echoes [Ecklund and Balsley, 1981; Röttger et al., 1988; Czechowsky et al., 1989; Cho et al., 1992] are still not well known. Both phenomena only occur in the polar summer mesosphere where the temperatures are unusually low. However there is conflicting evidence whether the occurrence of one is a requirement for the other [Jensen et al., 1988; Taylor et al., 1989]. One of the goals of the NLC91 campaign was to try and define what, if any, relationships exist between these two phenomena. This goal influenced the priorities of the different launch criteria based on PMSE seen by CUPRI and NLC seen by ground-based and air-borne observers. (See the overview paper by Goldberg et al. [1993].)

Since NLC was deemed the less probable event, and since the preparations of the second salvo would take more than a day, the initial launch criterion for the first salvo was the presence of NLC, regardless of whether PMSE was present. Although there were many periods of strong PMSE, no NLC was observed for the first week of the window, and subsequently, the criterion for the first salvo was relaxed to that of having either NLC or PMSE (or both). Two rocket salvos (Salvos B and C) were then flown into strong PMSE (only) events. NLCs were finally seen by the airborne observer just prior to midnight on August 9 at a time when CUPRI was detecting a single steady PMSE

Copyright 1993 by the American Geophysical Union.

Paper number 93GL01601

0094-8534/93/93GL-01601\$03.00 layer, and the third and final rocket salvo (Salvo A) was launched beginning at 22:53 UT. Herein we discuss the CUPRI configuration for NLC-91 and the observations of the PMSE event that was present during this salvo; two companion papers discuss the CUPRI data surrounding Salvos B and C [Cho et al., 1993; Miller et al., 1993].

\section{Brief CUPRI Description}

The 46.9-MHz CUPRI backscatter radar system that was configured for NLC-91 included a $50-\mathrm{kW}$ transmitter, three receiving antennas (one being common with the transmitting antenna), three phase coherent receivers, and a real-time Harris $\mathrm{H}-100$ computer for spectral processing, displays, and digital recording of the data. A 27-foot Winnebago served as a mobile laboratory for CUPRI. The radar controller was programmed to provide 16 -baud complementary phase coding of the transmitted $\mathrm{RF}$ pulses with a baud length of $2 \mu$ s that allowed us to achieve 300 -meter height resolution through the mesospheric region of interest. (The phase sequences are defined in Table 1 where the sign changes refer to $180^{\circ} \mathrm{RF}$ phase changes.) Our previous observations of PMSE were limited to a height resolution of about $1.5 \mathrm{~km}$ [Röttger et al., 1988]. The interpulse period (IPP) was $4 \mathrm{~ms}$. Coherent integration of 22 IPPs and subsequent 64-point FFTs resulted in a spectral frequency resolution of $180 \mathrm{mHz}$. Typically six spectra were averaged for a time resolution of $34 \mathrm{~s}$ and a SNR enhancement factor of 860 . This post-processing SNR is used in Figure 1; therefore, to get the SNR of the raw data one must subtract $10 \log 860=29 \mathrm{~dB}$ from the scale shown.

The transmitting antenna was a flat array of sixteen, 26-element strings of co-linear co-axial half-wave dipoles (COCOs) suspended a quarter wave above reflecting wires, yielding a two-way beam width of approximately $5^{\circ}$. The COCOs were oriented along east-west lines with a northsouth spacing of $3.2 \mathrm{~m}$ and fed as four groups of four. Insertion of additional incremental lengths of feed line to the different groups then allowed us to shift the beam direction $8^{\circ}$ north (or south), a change taking 1 to 2 minutes to accomplish. The two other receiving antennas consisted of arrays of four Yagis each, one placed a distance of $61.5 \mathrm{~m}$ north from the center of the main array, and the other $90 \mathrm{~m}$ east of the main array.

The received signals were mixed down to baseband with each yielding a pair of quadrature outputs, and these three

TABLE 1. 16-Baud Complementary Code

\begin{tabular}{cc}
\hline IPP & RF Phase Sequence \\
\hline 1 & +-+++---+-++-+++ \\
2 & +-+++----+--+--- \\
3 & -+---+++-+--+--- \\
4 & -+---++++-++-+++ \\
\hline
\end{tabular}




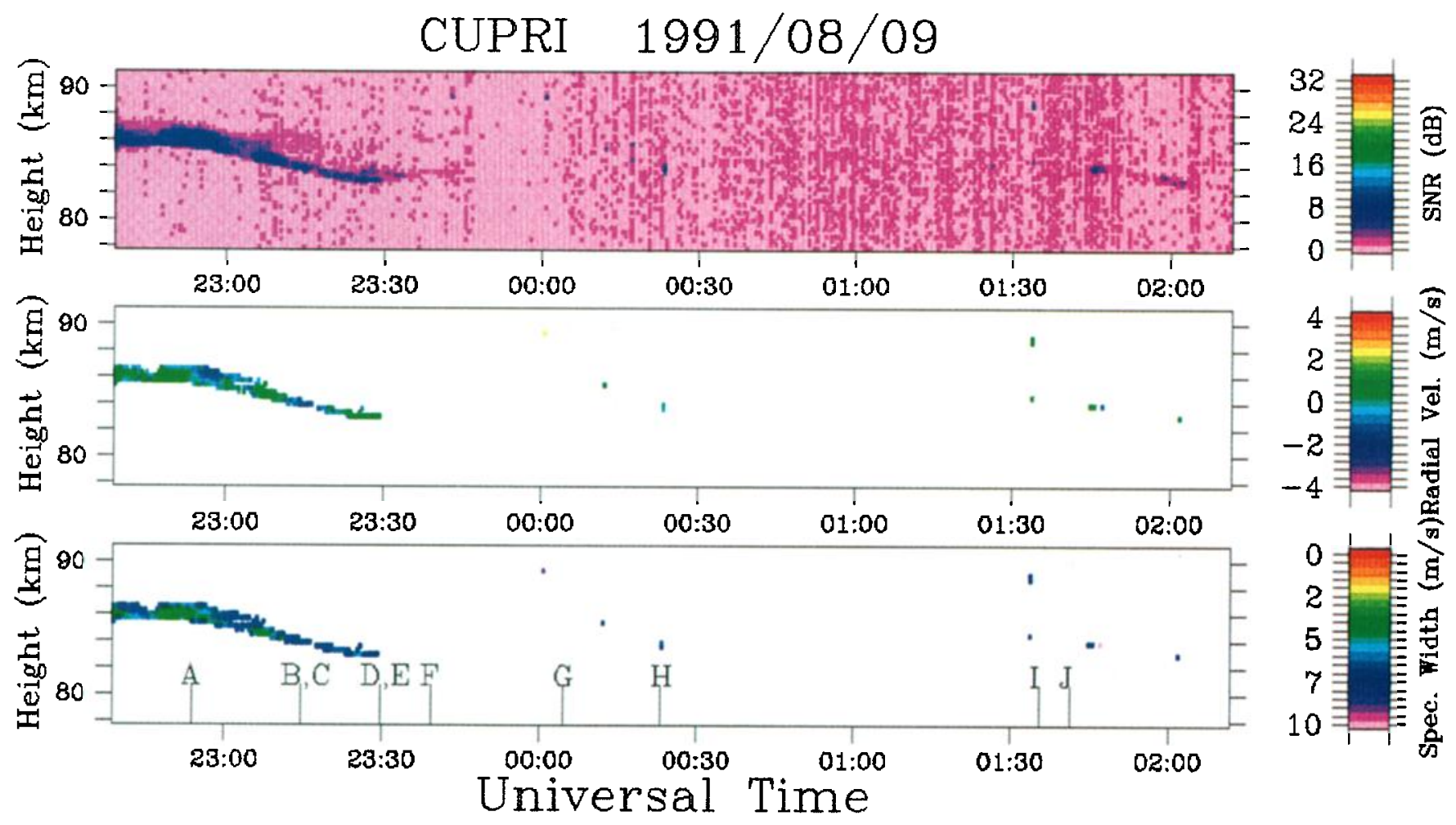

Fig. 1. CUPRI data during the Salvo A launch sequence. The top panel displays the post-processing signal-tonoise ratio versus altitude and time. The middle panel shows the radial velocity (positive is upward and negative is downward). The Doppler spectral width is displayed in the bottom panel.

pairs of receiver outputs were simultaneously digitized at $2 \mu \mathrm{s}$ intervals over a raster of 60 range gates and fed into the computer. (After decoding the complementary phase sequence, there were 45 usable ranges left.) Rastors of 12 noise samples and 24 transmitter pulse samples were also included. The raw samples were written to 8 mm Exabyte tapes with capacities of $2.2 \mathrm{~GB}$ each. The original raw data set contains over $300 \mathrm{~GB}$ for the whole campaign. Although the instantaneous data transfer rates reached $3 \mathrm{MB} / \mathrm{s}$, the average rate to tape was only about $145 \mathrm{kB} / \mathrm{s}$. The intelligent parallel $\mathrm{I} / \mathrm{O}$ channels of the Harris computer required less than one-half of one percent of the $\mathrm{CPU}$ time to sustain these rates, and so there were plenty of CPU cycles available for driving the concurrent display programs. Gray scale range-time-intensity (RTI) plots were dumped to a printer in the rocket control room (over a dedicated modem line) as well as to the units in the Winnebago, all in real-time. These served as primary input for launch decisions.

The radar interferometer technique that was implemented with the CUPRI system was pioneered at the Jicamarca Observatory in Peru for studying equatorial plasma instabilities [Farley et al., 1983; Kudeki et al., 1981], and can provide the location and tracking of individual scattering regions in addition to the more conventional Doppler spectra. This technique has also proved useful with CUPRI for mid-latitude sporadic-E studies [Riggin et al., 1986], auroral E-region work [Providakes et al., 1983; Providakes et al., 1985; Sahr et al., 1992], and other PMSE studies
[Hall et al., 1990; Röttger et al., 1990b; Hall, 1991; Cho, 1993].

\section{CUPRI Observations of PMSE}

CUPRI was installed near the Esrange, Sweden rocket launch facilities and became operational there on July 21 , 1991 following 2-1/2 weeks of PMSE observations from Troms $\emptyset$, Norway and the 3 days it took for the move. PMSE were observed for some portion of every day for the next 23 days until CUPRI was packed up for shipment back to the USA. The total time of mesospheric data recorded by the CUPRI was 264 hours. During this time, PMSE were present for a total of 140 hours, yielding an occurrence rate of $53 \%$. Although PMSE can occur any time, day or night, there does seem to be a reduced probability of occurance around 18:00 UT.

The PMSE layer observed by CUPRI during rocket Salvo $\mathrm{A}$ is shown in Figure 1. The times of each launch are marked in the lower panel and cross referenced in the overview paper by Goldberg et al. [1993]. The top panel is a range-time-intensity (RTI) plot of the signal-to-noise ratio. Although signal-to-noise ratios generally exceeded $20 \mathrm{~dB}$ at some time during almost every 24 hour period of observations, the maximum during this period was only $14 \mathrm{~dB}$ at 22:49 UT.

The first launch of this salvo occurred after this single steady PMSE layer had existed for about $30 \mathrm{~min}$. The criterion used to initiate the salvo, however, was the air-borne observation of NLC [Wälchli et al., 1993]. The signal-to- 
noise decreased after the first launch, and by 23:40 PMSE was extremely weak, and remained weak (or below our limits of detectability) for much of the remaining 3 hours of the salvo. The layer strengthened briefly at 01:30 which was just after the launches of DECIMALS B and Viper 8. The layer started at $86-87 \mathrm{~km}$ altitude, increased slightly in height around 22:48-22:55, and then fell to $83-84 \mathrm{~km}$ by $23: 30$. The second panel indicates very small Doppler velocities except for brief intervals near 22:55 and 23:15 when velocities of $3 \mathrm{~m} / \mathrm{s}$ downward were reached. However, the average measured Doppler velocity is only about $18 \mathrm{~cm} / \mathrm{s}$ downward, which is far too small to account for the $3 \mathrm{~km}$ drop in 20-25 minutes. Hence, the drop of the layer either represents an effect of a horizontal tilted structure moving through the beam, or a waning of the scatterers at one height and a generation of scatterers at a lower height. This is typical of previous results. (See, for example, Röttger et al. [1988].) Wind measurements taken by the falling sphere Viper 6 launched at 22:53 UT indicate that the horizontal wind at $83 \mathrm{~km}$ was blowing from ENE at about $50 \mathrm{~m} / \mathrm{s}$, which would imply a $2^{\circ}$ downward tilt of the PMSE layer in the ENE direction during the time of the DECIMALS A flight. The widths of the spectra were typically 4 to $6 \mathrm{~m} / \mathrm{s}$ within this layer.

The lower panel of Figure 1 shows the second moments (or widths) of the spectra. Since this method can smooth over the details in the spectra, we present high timeresolution Doppler spectrograms in Figure 2. Dynamically, the radar scattering region appears to have been calm relative to the conditions during Salvos B and C (see companion papers [Cho et al., 1993; Miller et al., 1993]). There are hints of the sawtooth-like discontinuities in the spectra in the lower three panels that were more evident during Salvo B [Cho et al., 1993] and which are fairly common features of PMSE [Röttger et al., 1990a]. We interpret this peculiar spectral feature to be a vertically distorted partial reflection layer which was advected horizontally across the radar beam. (See the more detailed discussion in [Cho et al., 1993]).

\section{Conclusions}

With the new and improved version of the CUPRI system, we were able to observe PMSE with a finer range resolution and higher effective sensitivity than before by using complementary phase coded RF pulses and $2 \mu$ s sampling. As an example of the PMSE occurring during the NLC-91 campaign, we have shown the morphology of the layer that occurred during the rocket salvo flown into a noctilucent cloud to set the stage for discussions of the in-situ measurements being reported in other papers of this special GRL issue. Because raw data was recorded for the entire NLC91 campaign, we have a great deal of flexibility in the data processing as dictated by different scientific objectives. In forthcoming papers we will examine the characteristics of PMSE in more detail.

Acknowledgments. We would like to thank the scientists and staff of the Swedish Esrange rocket facility for the support and friendships established during the NLC91 campaign. This work was supported under NASA Grant
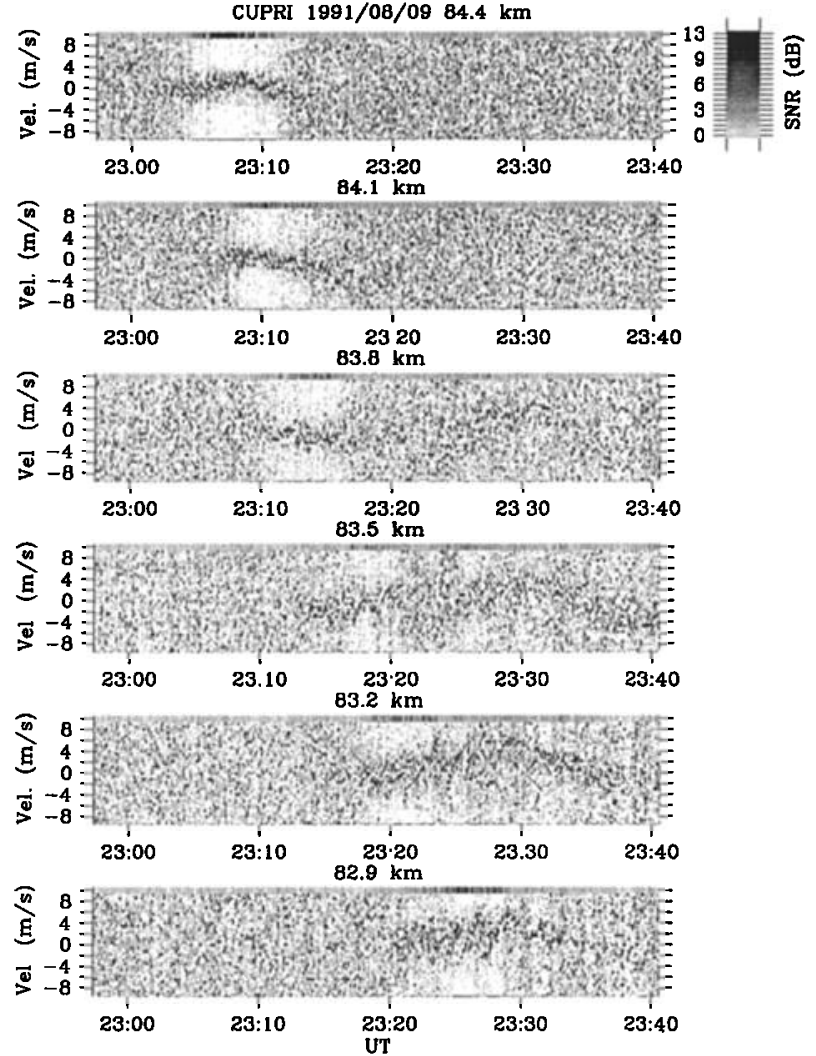

Fig. 2. CUPRI Doppler spectrograms for a selected range of heights. Each time strip is self-normalized and the corresponding SNR is given by a grey-scale bar at the top of each panel (the scale is given at top right). The time resolution is $5.6 \mathrm{~s}$. Only $\pm 9 \mathrm{~m} / \mathrm{s}$ of the Nyquist range of $\pm 18 \mathrm{~m} / \mathrm{s}$ is shown in this figure. Positive velocity is upward, negative is downward.

NAG5-666 and NSF Grants ATM-9021915 and ATM9217007 to Cornell University. CAM was supported addtionally by an NSF Graduate Research Fellowship.

\section{References}

Cho, J. Y. N., Radar Scattering from the Summer Polar Mesosphere: Theory and Observations. PhD thesis, Cornell Univ., Ithaca, N.Y., 1993.

Cho, J. Y. N., T. M. Hall, and M. C. Kelley, On the role of charged aerosols in polar mesosphere summer echoes, J. Geophys. Res., 97, 875, 1992.

Cho, J. Y. N., W. E. Swartz, M. C. Kelley, and C. A. Miller, CUPRI observations of PMSE during Salvo B of NLC92: Evidence of both partial reflection and turbulent scatter, Geophys. Res. Lett., 1993, (submitted).

Czechowsky, P., I. M. Reid, R. Rüster, and G. Schmidt, VHF radar echoes observed in the summer and winter polar mesosphere over Andøya, Norway, J. Geophys. Res., 94, 5199, 1989.

Ecklund, W. L., and B. B. Balsley, Long-term observations of the Arctic mesosphere with the MST radar at Poker Flat, Alaska, J. Geophys. Res., 86, 7775, 1981.

Farley, D. T., H. M. Ierkic, and B. G. Fejer, Radar interferometry: A new technique for studying plasma turbulence, J. Geophys. Res., 86, 1467, 1983. 
Gadsden, M., and W. Schröder, Noctilucent Clouds, Springer-Verlag, Berlin, 1989.

Goldberg, R. A., E. Kopp, G. Witt, and W. E. Swartz, An overview of NLC-91: A rocket and radar study of noctilucent clouds and polar mesosphere summer echoes, Geophys. Res. Lett., 1993, (submitted).

Hall, T., M. C. Kelley, and W. E. Swartz, 50-MHz radar interferometer results from the polar summer mesosphere, EOS Trans. $A G U, 71,572,1990$.

Hall, T. M., Radar Observations and Dynamics of the Polar Summer Mesosphere. PhD thesis, Cornell Univ., Ithaca, N.Y., 1991.

Jensen, E. J., G. E. Thomas, and B. B. Balsley, On the statistical correlation between polar mesospheric cloud occurrence and enhanced mesospheric radar echoes, Geophys. Res. Lett., 15, 315, 1988.

Kudeki, E., B. G. Fejer, D. T. Farley, and H. M. Ierkic, Interferometer studies of equatorial $\mathrm{F}$ region irregularities and drifts, Geophys. Res. Lett., 8, 377, 1981.

Miller, C. A., J. Y. N. Cho, and W. E. Swartz, CUPRI observations of PMSE during Salvo C of NLC-91: Evidence of a depressed mesopause temperature, Geophys. Res. Lett., 1993, (submitted).

Providakes, J., D. T. Farley, W. E. Swartz, and D. Riggin, Plasma irregularities associated with a morning discrete auroral arc: Radar interferometer observations and theory, J. Geophys. Res., 90, 7513, 1985.

Providakes, J. F., W. E. Swartz, D. T. Farley, and B. G. Fejer, First VHF auroral interferometer observations, Geophys. Res. Lett., 10, 401, 1983.

Riggin, D., W. E. Swartz, J. Providakes, and D. T. Farley, Radar studies of long wavelength waves associated with midlatitude sporadic-E layers, J. Geophys. Res., 91, $8011,1986$.

Röttger, J., C. La Hoz, S. J. Franke, and C. H. Liu, Steepening of reflectivity structures detected in highresolution Doppler spectra of polar mesosphere summer echoes (PMSE) observed with the EISCAT 224-MHz radar, J. Atmos. Terr. Phys., 52, 939, 1990a.

Röttger, J., C. La Hoz, M. C. Kelley, U.-P. Hoppe, and C. Hall, The structure and dynamics of polar mesosphere summer echoes observed with the EISCAT 224MHz radar, Geophys. Res. Lett., 15, 1353, 1988.

Röttger, J., M. T. Rietveld, C. La Hoz, T. Hall, M. C. Kelley, and W. E. Swartz, Polar mesosphere summer echoes observed with the EISCAT $933-\mathrm{MHz}$ radar and the CUPRI 46.9-MHz radar, their similarity to $224-\mathrm{MHz}$ radar echoes and their relation to turbulence and electron density profiles, Radio Sci., 25, 671, $1990 b$.

Sahr, J. D., D. T. Farley, W. E. Swartz, J. F. Providakes, and R. F. Pfaff, Observations of 3-m auroral irregularities during the ERRRIS campaigns, J. Atmos. Terr. Phys., 54, 809, 1992.

Taylor, M. J., A. P. van Eyken, H. Rishbeth, G. Witt, N. Witt, and M. A. Clilverd, Simultaneous observations of noctilucent clouds and polar mesospheric radar echoes: Evidence for non-correlation, Planet. Space Sci., 37, 1013, 1989.

Thomas, G. E., Mesospheric clouds and the physics of the mesopause region, Rev. Geophys., 29, 553, 1991.

Wälchli, U., J. Stegman, G. Witt, J. Y. N. Cho, C. A. Miller, M. C. Kelley, and W. E. Swartz, First height comparisons of noctilucent clouds and simultaneous PMSE, Geophys. Res. Lett., 1993, (submitted).

Witt, G., The nature of noctilucent clouds, Space Res., 9, $157,1969$.

W. E. Swartz, J. Y. N. Cho, and C. A. Miller, School of Electrical Engineering, Engineering and Theory Center Bldg., Cornell University, Ithaca, NY 14853-3801.

(Received December 28, 1992; accepted June 3, 1993.) 